\title{
Desenvolvimento de um novo produto cerâmico para pavimentação de passeios e áreas públicas
}

\author{
Development of a new ceramic product for paving \\ footways and public areas
}

\author{
Lilian Lima Dias \\ Ana Paula Margarido Menegazzo \\ Eduardo Quinteiro \\ Marcos Antônio Serafim
}

\section{Resumo}

$\mathbf{M}$

obilidade e segurança são temas cada vez mais discutidos nos grandes centros urbanos, e as iniciativas nesse universo devem prever soluções práticas e econômicas, que gerem benefícios para os cidadãos. O pavimento, um dos fatores para a qualidade urbana, é a via de acesso indispensável para garantir o direito de ir e vir. Entre as soluções, o pavimento intertravado se destaca como um dos produtos mais recomendados na pavimentação das calçadas e áreas públicas. Em países da Europa e da América Latina a pavimentação com sistemas intertravados de cerâmicas é amplamente utilizada, porém essa prática ainda é pouco observada no Brasil, pela inexistência desse produto no mercado local. Desse modo, o objetivo deste projeto foi o desenvolvimento de pavimentos intertravados de cerâmica visando ao uso em passeios e áreas públicas. Também foram adicionados ao novo produto desenvolvido resíduos queimados oriundos do próprio processo de fabricação, os quais são chamados de cacos ou chamote, para diminuir a quantidade de material a ser descartado no meio ambiente. Após os resultados positivos na caracterização dos produtos, foram criados novos designs para essa tipologia de produtos, os quais foram produzidos em escala laboratorial.

Palavras-chaves: Pavimentos intertravados. Design cerâmico. Calçamento.

Lilian Lima Dias Centro Cerâmico do Brasil Santa Gertrudes - SP - Brasil

Ana Paula Margarido Menegazzo Centro Cerâmico do Brasil Santa Gertrudes - SP - Brasil

Eduardo Quinteiro Universidade Federal de São Paulo São José dos Campos - SP - Brasil

Marcos Antônio Serafim Centro Cerâmico do Brasil Santa Gertrudes - SP - Brasil

Recebido em 15/11/14 Aceito em 13/05/16

\section{Abstract}

Mobility and security issues are increasingly discussed in the major urban centers and initiatives in this universe should provide practical and economical solutions that generate benefits for citizens. The pavement, one of the factors for urban quality, is the essential to ensuring access to the right to come and go. Among these solutions, the interlocking pavement stands out as being one of the most recommended products on the paving of sidewalks and public areas. In some countries in Europe and Latin America ceramics interlocking paving systems are widely used, but this practice is still little found Brazil in by the absence of this product in the Brazilian market. Thus the purpose of this work was to develop ceramics interlocking paving for use on sidewalks and public areas. Also it was added to the new product developed burned waste coming from the manufacturing process, which are called chamotte aimed at reducing the material to be discarded into the environment. After the positive results for characterizing the products, new designs for this type of products were created, which were produced in laboratory scale.

Keywords: Interlocked paver. Ceramic design. Paviment.
\end{abstract}




\section{Introdução}

A indústria de cerâmica vermelha caracteriza-se pela cor de seus produtos, representados por tijolos, blocos, telhas, tubos, lajes para forros, lajotas, vasos ornamentais e agregados leves de argila expandida, entre outros.

Atualmente o país experimenta uma demanda crescente nas políticas públicas, que exige cada vez mais produtos conformes às normas de qualidade existentes, e consumidores mais exigentes em relação à busca de novos produtos. Por outro lado, há empresas com pouca oferta de produtos e muita concorrência entre as próprias indústrias cerâmicas e outros materiais não cerâmicos para cobertura e pavimentação de áreas públicas e de grande tráfego. Entre os principais produtos cerâmicos utilizados na construção civil destacam-se tijolos, blocos, telhas, tubos, lajes para forros, lajotas e outros. No caso da construção civil, os produtos maciçamente consumidos são os blocos, tanto estruturais como de vedação, e as telhas. Esses produtos, normalmente, apresentam baixo valor agregado devido à baixa diferenciação.

A Associação Nacional da Indústria Cerâmica (ASSOCIAÇÃO..., 2014) aponta que o setor conta com cerca de 6.903 empresas entre cerâmicas e olarias, sendo responsável por mais de 293 mil empregos diretos e 900 mil indiretos, e gerando um faturamento anual de R\$ 18 bilhões $(4,8 \%$ do faturamento da indústria da construção civil). Essas unidades encontram-se muito pulverizadas, sendo encontradas em toda a extensão nacional, e em sua maioria são micro, pequenas e médias empresas que utilizam processos produtivos tradicionais. A produção e a comercialização da cerâmica vermelha fazem com que exista uma configuração geográfica descentralizada de empresas, que se agregam nos chamados arranjos produtivos locais (APL), cujas distâncias da extração da matéria-prima e da comercialização dos produtos são curtas.

$\mathrm{O}$ alto consumo de produtos de cerâmica vermelha e a utilização de processos produtivos tradicionais levam a uma concorrência acirrada entre as empresaa fabricantes. Como esforço para reverter esse quadro, vários empresários passaram a investir em novas tecnologias, capacitação da mão de obra e melhoria da qualidade dos produtos, a fim de sobreviver em um mercado altamente competitivo.

Diante desse cenário, detectou-se a necessidade de se pensarem produtos bem resolvidos, tanto no ponto de vista da qualidade e do desempenho quanto do design. Neste trabalho é apresentada uma alternativa para empresas produtoras de telhas e blocos cerâmicos diversificarem seus produtos com o desenvolvimento de pavimentos cerâmicos do tipo intertravado para áreas públicas. Há poucas empresas brasileiras que fabricam os pavimentos cerâmicos do tipo intertravado, porém os produtos existentes restringem-se aos modelos tradicionalmente feitos em cimento. Também não são observados estudos das características técnicas realizados nos pavimentos cerâmicos do tipo intertravado existentes no mercado nacional. Dessa forma, o produto desenvolvido poderá ser considerado um produto inovador quanto a seu design. Tendo como ponto de partida a experiência de outros países da Europa e da América Latina na fabricação de produtos dessa tipologia, propõe-se um novo caminho com a criação, inovação e desenvolvimento de produtos diferenciados e com maior valor agregado, que tem por objetivo elevar a competitividade e assegurar a sobrevivência de muitas das pequenas e médias empresas de cerâmica vermelha, imprimindo a elas uma identificação regional e nacional.

Do ponto de vista da construção, da arquitetura e do paisagismo, esse tipo de produto apresenta benefícios como vida útil longa, resistência mecânica elevada, cores naturais exuberantes e facilidade de implantação e reparação. Soma-se a essas características o fato de ser um produto permeável, o qual favorece a drenagem das águas das chuvas.

Ainda neste trabalho se propõe a adição de resíduos queimados descartados pela própria indústria cerâmica no desenvolvimento dos pavimentos intertravados, com o objetivo de dar uma destinação mais nobre e adequada a esses rejeitos, de forma a contribuir também para a preservação do meio ambiente.

\section{Revisão bibliográfica}

\section{Pavimentos intertravados}

Os pavimentos intertravados, ou como descreve a NBR 9781 (ABNT, 2013), peças de concreto para pavimentação, são peças pré-moldadas de concreto utilizadas na construção de pavimentos ou calçamentos. Sua camada superficial apresenta acabamento confortável para o trânsito de pessoas, e sua estrutura permite suportar o trânsito de veículos leves ou pesados, conforme a categoria e a aplicação (FERNANDES, 2013).

A pavimentação intertravada tem como principal característica $\mathrm{o}$ fato $\mathrm{de}$ as peças serem simplesmente assentadas, devidamente confinadas sobre uma camada de areia, que serve de

156 Dias, L. L.; Menegazzo, A. P. M.; Quinteiro, E.; Serafim, M. A. 
regularização da base e atua na distribuição das cargas e acomodação das peças.

O conceito básico desse tipo de pavimentação é o intertravamento, ou seja, a transmissão de parte da carga de uma peça para a peça vizinha através do atrito lateral entre elas. Outra característica desse sistema é o fato de ser permeável, pois permite a passagem de parte da água da chuva para o solo através das juntas. A Figura 1 mostra o assentamento de peças intertravadas.

No Brasil, a técnica de pavimentação com blocos cimentícios surge nos anos 1970, ainda bastante incipiente e muitas vezes sem obedecer a critérios técnicos mínimos (HALLACK, 2001).

Cruz (2003) ratifica essa colocação e descreve uma evolução da pavimentação desde os tijolos de argila da Mesopotâmia de 5.000 anos atrás. Relata que no Brasil o uso de pavimentação iniciou-se por blocos com os pavimentos de paralelepípedos e os calçamentos do tipo pé de moleque (a exemplo da cidade de Paraty, no estado do Rio de Janeiro), a partir de 1600. Evoluiu para os blocos de tijolos de madeira, no início do século XIX, que objetivavam diminuir o nível de ruído do atrito das rodas de ferro das carruagens, e, posteriormente, para o uso das peças pré-moldadas de concreto, que, como já dito, passaram a ser desenvolvidas no Brasil a partir da década de 1970

Atualmente esse tipo de pavimentação encontra nos programas de urbanização, decretos e leis grandes aliados de incentivo ao uso dele em áreas de passeios públicos.

Os blocos intertravados possuem uma vida útil bastante considerável, mas, além dessa característica, outros fatores de desempenho pesam a favor do uso desse tipo de produto em vias públicas.
Hallack (2001) descreve essas características como qualidades estéticas, versatilidade do material e facilidade de estocagem, e ainda destaca outras características importantes dos blocos intertravados:

(a) permitem o uso imediato do pavimento logo após seu assentamento;

(b) possuem capacidade para manter a sequência do pavimento mesmo quando sujeitos a acomodações do subleito;

(c) possibilitam fácil reparação, facilidade de acesso às instalações subterrâneas sem marcas aparentes, reutilização das peças, fácil execução, alta resistência à abrasão, resistência ao ataque de óleos e combustíveis, e baixa manutenção;

(d) não há exigência de mão de obra e/ou equipamentos especiais;

(e) proporcionam facilidade na incorporação de sinalização horizontal em função das peças coloridas; e

(f) apresentam menor absorção da luz solar, além de ser o pavimento mais permeável, o que proporciona microdrenagem das águas pluviais.

Todas as características relatadas acima são consideradas para pisos intertravados compostos de material cimentício, ou mais especificamente o cimento do tipo CP (Cimento Portland) 3.

Os blocos intertravados para passeios, além dos formatos variados, que possibilitam uma diversidade de paginações, variam também quanto a suas espessuras, que são definidas em função do local de uso e consequentemente das cargas geradas sobre eles $\left(\mathrm{kg} / \mathrm{m}^{2}\right)$. Medeiros $(2008$, p. 1) afirma que "[...] os pavers são produzidos para atingir alta resistência à compressão (35 MPa a 50 $\mathrm{MPa})$, igual ou maior que das estruturas dos edifícios [...]".

Figura 1 - Assentamento de peças intertravadas

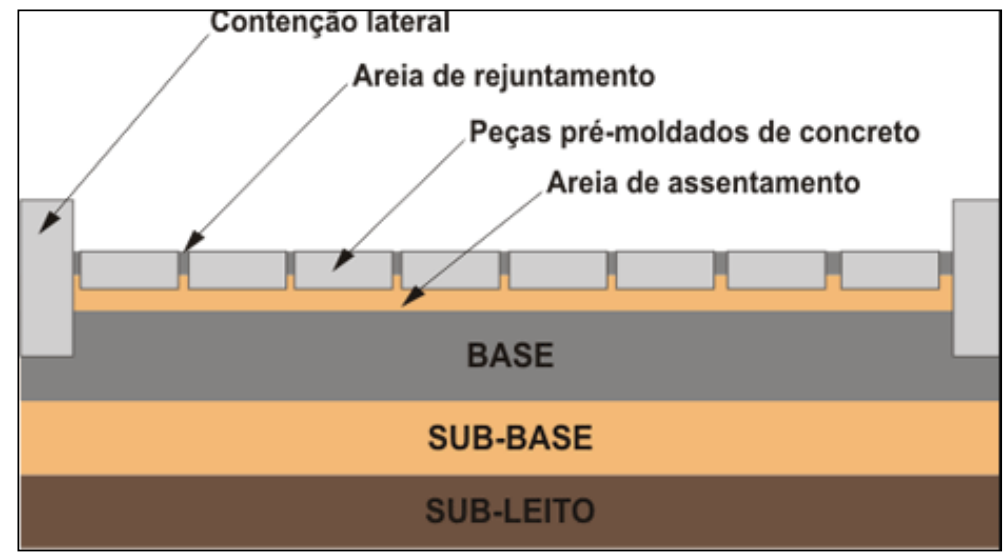

Fonte: Pedreirão (2014). 


\section{Intertravamento do sistema}

$\mathrm{O}$ processo de assentamento das peças garante a esse tipo de pavimentação uma de suas características mais importantes, o intertravamento. A ABCP (ASSOCIAÇÃO..., 2009) define intertravamento como a capacidade que os blocos adquirem de resistir a movimentos de deslocamento individual, seja ele vertical, horizontal ou de rotação em relação a seus vizinhos. Para que se consiga o intertravamento, duas condições são indispensáveis: contenção lateral e junta preenchida com areia.

Dessa maneira, o intertravamento acontece em função de um sistema de assentamento das peças, e para que ele ocorra todo esse sistema deve estar integrado de maneira eficiente. Existem três formas de intertravamento que permitem que os blocos resistam aos movimentos de deslocamento. São eles:

(a) intertravamento horizontal, que é a incapacidade de deslocamento horizontal de uma peça em relação às peças vizinhas, em todo tipo de arranjo de assentamento. O formato e o arranjo de assentamento das peças sobre a camada de areia estão diretamente relacionados a esse fenômeno, contribuindo na distribuição dos esforços de cisalhamento horizontal sob a atuação do tráfego, especialmente em áreas de frenagem e aceleração. O responsável pelo adequado intertravamento horizontal é o preenchimento das juntas entre as peças, que deve ser fino e bem compactado;

(b) intertravamento vertical, que é a restrição das peças ao movimento vertical em relação às peças vizinhas. Esse tipo de intertravamento é obtido através dos esforços de tensão tangencial absorvidos pelo rejuntamento de areia entre as peças e a capacidade estrutural das camadas inferiores do pavimento, mediante o uso de peças especiais com formatos e encaixes reentrantes. Dessa forma, quando houver uma carga vertical sobre a peça existe um contato do tipo machofêmea distribuindo os esforços para as peças vizinhas. Existe também o tipo de intertravamento vertical que independe do formato das peças. Este ocorre em função da malha de juntas formadas pelos grãos de areia bem compactados lateralmente e a estabilidade estrutural do colchão de areia compactado e confinado. Esse fenômeno ocorre, geralmente, em função do tipo e da frequência do tráfego, especialmente em áreas de frenagem, aceleração e tensões radiais de pneus (curvas); e

(c) intertravamento rotacional, obtido pela espessura das juntas entre as peças e o consequente confinamento oferecido pelas peças vizinhas, bem como pelo tipo e qualidade de areia utilizado no rejuntamento.

O desempenho da pavimentação que se utiliza de um sistema intertravado variará em função das condições de cada um dos componentes constituintes desse sistema.

Conclui-se que é o intertravamento que confere resistência a esses pavimentos, diferenciando-os dos demais, e que um bom intertravamento atribui aos blocos a capacidade de transmitir as cargas superficiais aplicadas em pequenas áreas. A propriedade de distribuição de cargas vai melhorando com o uso do pavimento, ou seja, em função do tempo é produzido, progressivamente, um estado de travamento total, em que a camada de rolamento passa a adquirir maior rigidez e os blocos deixam de constituir meramente a camada de rolamento e se transformam numa camada estrutural.

Os formatos e paginações dos pavimentos intertravados agregam valores estéticos inegáveis em função dos múltiplos formatos e possibilidades de paginação. No entanto, não há consenso na influência dos formatos das peças no desempenho do sistema de pavimentação intertravado. Para Müller (2005), o formato dos blocos não influencia significativamente no desempenho e no mecanismo funcional dos pavimentos. Hallack (2001) pondera, no entanto, que o formato das peças influi no desempenho do pavimento e que a escolha do tipo de bloco deve levar em consideração a melhor capacidade de distribuição de tensões e a facilidade de assentamento.

Já foi visto que o intertravamento depende em muito da qualidade de assentamento dos elementos que constituem o sistema. A capacidade de intertravar, sobretudo verticalmente, pode ser definida pelo desenho do bloco, e sua espessura influencia na determinação de carga suportada. Em se tratando de calçadas, não há determinação normativa sobre o formato das peças, mas é salientada a capacidade de intertravamento delas.

\section{Pavimento intertravado de cerâmica ou adoquim brasileiro}

O piso intertravado de cerâmica já utilizado no exterior, mas ainda raro no Brasil, onde também se adota o nome de adoquim, é processado com o uso de diferentes tipos de argila.

As reservas de argila para cerâmica vermelha são de grande porte e distribuem-se por praticamente todas as regiões do país, matéria-prima que representa entre $40 \%$ e $50 \%$ das substâncias minerais produzidas no país.

158 Dias, L. L.; Menegazzo, A. P. M.; Quinteiro, E.; Serafim, M. A. 
Todas as vantagens apresentadas para os intertravados cimentícios também são aplicadas ao intertravado de cerâmica. Uma vantagem do pavimento intertravado de cerâmica em relação ao confeccionado com concreto é dispensar o uso de corantes, pois os produtos apresentam um aspecto rústico atualmente muito valorizado no mercado e uma coloração natural que pode variar de vermelha a cinza, de acordo com o tipo de argila utilizada na composição da massa. Do ponto de vista arquitetônico e paisagístico, as formas, cores e texturas desses blocos de assentamento também são grandes aliadas para compor paisagens urbanas mais bonitas e versáteis, haja vista o fato de a sinalização poder ser incorporada ao pavimento.

O uso do rejeito de cerâmica queimada e quebrada no próprio processo produtivo ou advinda de outras empresas, conhecido como "chamote", vai possibilitar a valorização de um resíduo que é geralmente descartado. Esses rejeitos normalmente são depositados no próprio pátio das indústrias ou utilizados na pavimentação de estradas de terra, ou ainda moídos para o recobrimento de quadras de tênis de saibro. Define-se chamote como o material cerâmico descartado após a etapa de queima e submetido a um processo de trituramento e moagem.

\section{Materiais e métodos}

Para o desenvolvimento deste estudo foi utilizada uma argila plástica da região de Santa Gertrudes, SP, utilizada na fabricação de placas cerâmicas do grupo AIII (absorção de água > 10\%), também conhecidas como lajotas.

Os corpos de prova para este estudo foram obtidos por extrusão em laboratório utilizando-se uma maromba a vácuo e adicionando-se rejeitos (chamote) da própria indústria fabricante de lajotas na quantidade de $10 \%$ e com granulometria passante pela malha $\mathrm{ABNT} \mathrm{n}^{\mathrm{o}} 100$ (abertura 0,150 $\mathrm{mm}$ ) e retida na de $\mathrm{n}^{\circ} 200$ (abertura 0,075 mm). A definição dessa granulometria e desse percentual foi determinada em um estudo desenvolvido no projeto de pesquisa "Desenvolvimento de um novo conceito para bloquetes e telhas cerâmicas: produtos inovadores e ambientalmente responsáveis", do Edital MCT/CNPq n 65/2009 Entidades Setoriais de Apoio a PD\&I nas Empresas. Utilizou-se como padrão a argila extrudada sem a adição dos rejeitos (chamote).

Os teores de umidade adicionados à massa plástica para extrusão variaram de acordo com a proporção de rejeitos adicionados, buscando-se a obtenção de uma boa trabalhabilidade para esse método de conformação. Neste trabalho a umidade utilizada foi de $24 \%$ e $27 \%$ para a massa sem adição de rejeitos (padrão) e com adição de $10 \%$ de rejeitos respectivamente.

As massas umidificadas foram passadas duas vezes em laminador, com a finalidade de promover a melhor desaeração e homogeneização das massas para extrusão. Todos os corpos de prova obtidos laboratorialmente tinham o formato prismático, com secção de corte retangular de $50 \mathrm{~mm}$, comprimento aproximado de $100 \mathrm{~mm}$ e espessura de $10 \mathrm{~mm}$.

A secagem transcorreu inicialmente em temperatura ambiente por $24 \mathrm{~h}$, sendo posteriormente concluída em estufa a $100{ }^{\circ} \mathrm{C}$, visando extrair a água da plasticidade e a água dos poros.

Os corpos de prova foram então queimados em forno laboratorial seguindo-se um ciclo de queima com temperaturas máximas de $850{ }^{\circ} \mathrm{C}, 900^{\circ} \mathrm{C}, 950$ ${ }^{\circ} \mathrm{C}$ e $1.000{ }^{\circ} \mathrm{C}$. A velocidade de aquecimento utilizada foi de $25{ }^{\circ} \mathrm{C} / \mathrm{min}$, e a permanência na temperatura máxima foi de $1 \mathrm{~min}$.

Para os corpos de prova obtidos após a queima foram realizadas as seguintes caracterizações, segundo procedimento da NBR 13818 (ABNT, 1997):

(a) absorção de água (AA);

(b) módulo de resistência à flexão em três pontos (MRF);

(c) resistência à abrasão profunda $(\mathrm{ABP})$;

(d) resistência ao ataque químico (ATQ);

(e) retração linear de queima (RLq); e

(f) expansão por umidade (EPU).

Ressalta-se a inexistência de uma norma técnica brasileira para essa tipologia de produtos, sendo por isso adotada para a caracterização dos corpos de prova a norma de placas cerâmicas para revestimentos NBR 13818 (ABNT, 1997).

Depois da caracterização dos corpos de prova e de uma pesquisa dos modelos de intertravados de concreto disponíveis no mercado foram criados os modelos em cerâmica. A partir desses modelos foram desenvolvidos os moldes para a extrusora, chamados de boquilhas, para o início do processo de obtenção dos produtos em escala laboratorial. Os produtos foram confeccionados na escala de 1:3 e com espessura de $20 \mathrm{~mm}$, seguindo-se o mesmo procedimento de preparação e extrusão da massa descrito anteriormente, e queimados na temperatura de $950^{\circ} \mathrm{C}$.

Além dos resultados técnicos obtidos nos ensaios laboratoriais foi possível também fazer uma avaliação do comportamento estético dos 
pavimentos intertravados de cerâmica desenvolvidos em sua pavimentação.

O passo seguinte foi a criação de uma identidade visual (logotipo) para essa nova tipologia de produto, ou seja, uma marca que simbolizasse o produto desenvolvido, utilizando-se os recursos de estudos e pesquisas sobre o produto.

\section{Resultados}

\section{Caracterização do produto extrudado}

As Figuras $2 \mathrm{a}$ e $2 \mathrm{~b}$ mostram o rejeito (chamote) com granulometria passante pela malha $\mathrm{ABNT} \mathrm{n}^{\circ}$ 100 e retido na de $n^{0} 200$, e os corpos de prova após a queima.

As curvas de gresificação são mostradas comparativamente na Figura 3 para a amostra sem rejeito e para a amostra contendo $10 \%$ de rejeito. Pode-se observar uma sensível diferença entre a evolução da absorção de água com o aumento da temperatura. Em todo o intervalo de temperatura investigado a formulação sem resíduo apresentou menores valores de absorção de água. A diferença de absorção de água para as amostras sem e com rejeito não chega a $1 \%$ para uma mesma temperatura em todo o intervalo de queima utilizado $\left(850{ }^{\circ} \mathrm{C}\right.$ e $\left.1.000{ }^{\circ} \mathrm{C}\right)$. Os valores médios de absorção de água variaram de cerca de $16 \%$ (a $850^{\circ} \mathrm{C}$ ) até cerca de $13 \%$ (a $1.000^{\circ} \mathrm{C}$ ).

Quanto à retração linear de queima (Figura 3), para nenhuma das amostras (sem rejeitos e com $10 \%$ de rejeitos) excedeu-se o valor de $2 \%$. Isso mostra a possibilidade de se efetuar um bom controle dimensional das peças produzidas. Os valores médios de retração linear para a formulação sem rejeitos, em todo o intervalo de queima utilizado $\left(850{ }^{\circ} \mathrm{C}\right.$ e $\left.1.000{ }^{\circ} \mathrm{C}\right)$, mostrou pouca variação nas dimensões dos corpos de prova. Já para as amostras com $10 \%$ de rejeito observa-se uma variação mais significativa, principalmente a partir de $900{ }^{\circ} \mathrm{C}$.

Figura 2 - Rejeito utilizado neste trabalho e os corpos de prova após a queima

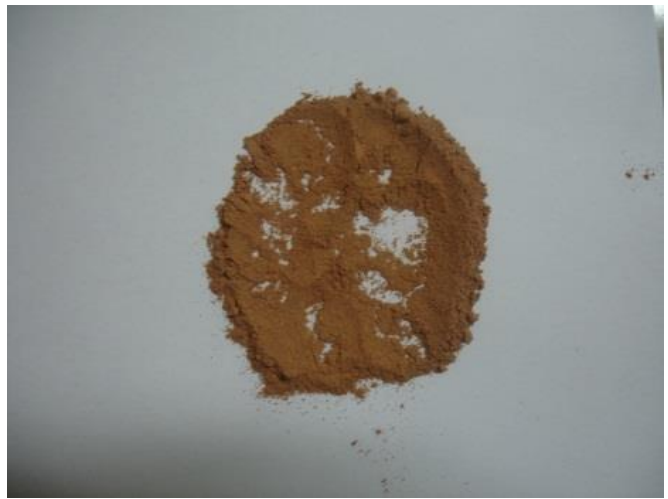

(a)

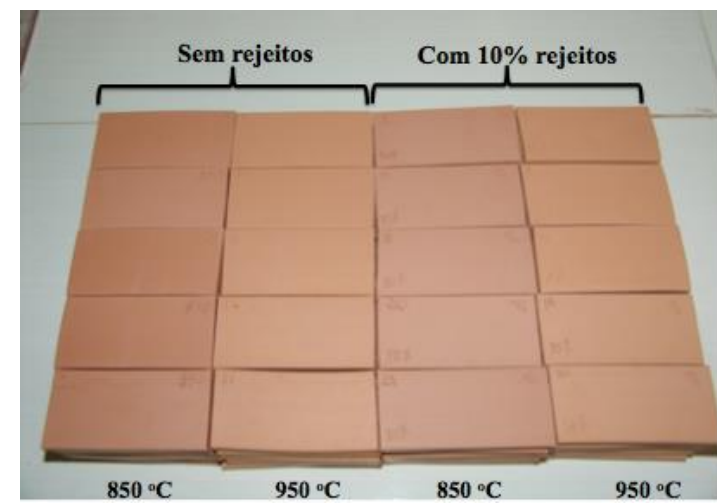

(b)

Figura 3 - Curvas de gresificação mostrando comportamento simultâneo da evolução da retração linear de queima (RLq) e absorção de água com a temperatura

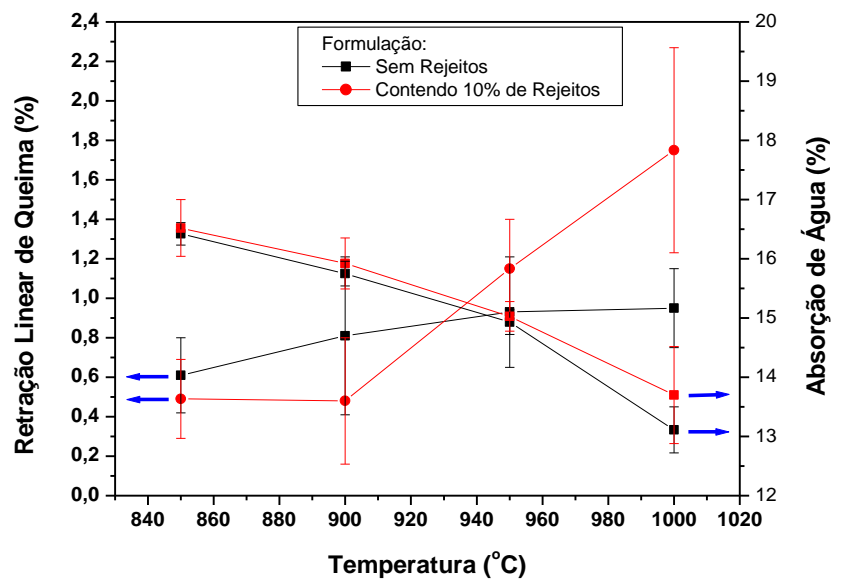

160 Dias, L. L.; Menegazzo, A. P. M.; Quinteiro, E.; Serafim, M. A. 
A magnitude das diferenças observadas no comportamento de gresificação com a adição do rejeito leva a concluir que seu uso não representará dificuldades tecnológicas no que diz respeito ao comportamento de queima e às características dimensionais dos produtos denominados pavimentos intertravados de cerâmica.

Não foram observadas diferenças significativas nos valores obtidos de módulo de resistência à flexão (MRF) e resistência à abrasão profunda com e sem adição dos rejeitos às massas extrudadas (Figuras 4 e 5 respectivamente). Como esperado, com a evolução da temperatura máxima de queima, os valores médios de resistência à flexão tenderam a aumentar, e os valores de material removido no processo de abrasão, a diminuir. A norma europeia UNE-EN 1344 (ASOCIACIÓN...,
2002), específica para o produto adoquim determina que o volume médio de material removido não poderá ser superior a $2.100 \mathrm{~mm}^{3}$. Comparando-se os resultados da resistência à abrasão (máximo de $2.200 \mathrm{~mm}^{3}$ e mínimo de 1.100 $\mathrm{mm}^{3}$ ) com o determinado na UNE-EN 1344 (ASOCIACIÓN..., 2002), observa-se o atendimento desta para os produtos queimados em temperaturas superiores a $900{ }^{\circ} \mathrm{C}$. Embora a norma europeia não especifique valores para resistência à flexão, se comparamos esses resultados com o valor determinado para as placas cerâmicas extrudadas do grupo de absorção de água AIII descritas na NBR 13818 (ABNT, 1997), cujo valor médio deverá ser maior ou igual a $8 \mathrm{MPa}$, verificase que as amostras atendem a essa característica para toda a faixa de temperatura estudada.

\section{Figura 4 - Evolução do módulo de resistência à flexão (MRF) com a temperatura de queima}

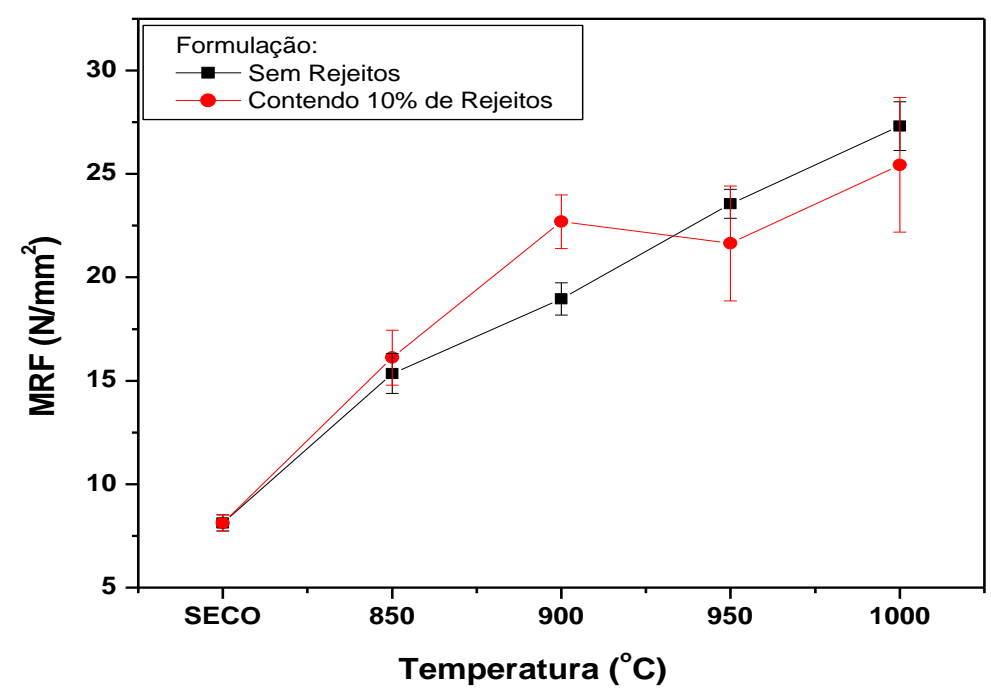

Figura 5 - Evolução da resistência à abrasão profunda (ABP) com a temperatura de queima

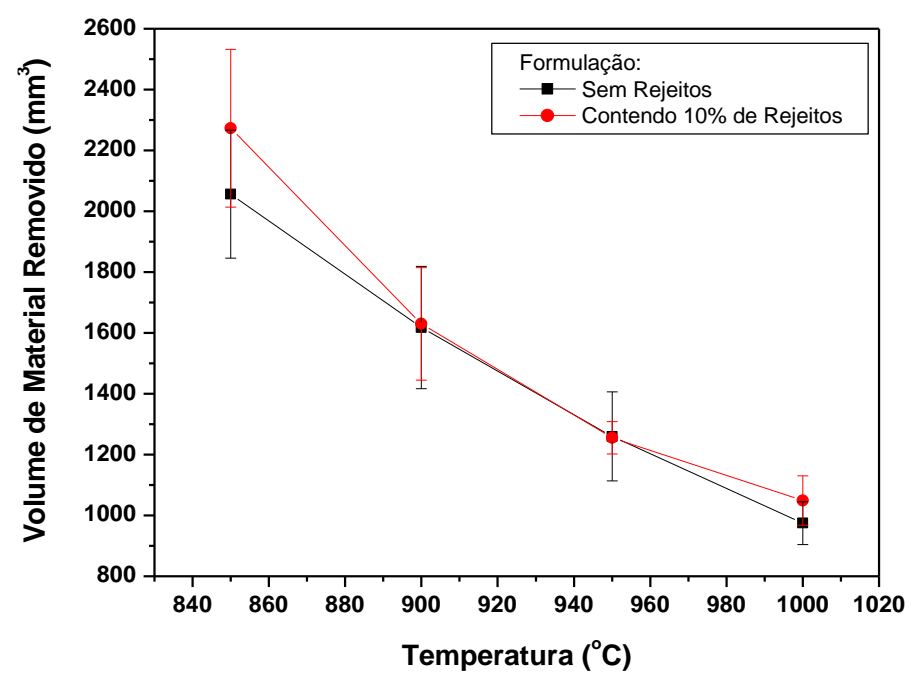


Uma característica importante para os produtos fabricados com material argiloso sinterizado é a expansão por umidade (EPU). Esta corresponde ao aumento de dimensões sofrido pelo produto da queima pela hidratação de fases vítreas e amorfas. Observa-se na Figura 6 que os valores obtidos para os corpos de prova não excedem $0,8 \%$ de expansão por umidade (EPU). Esse valor é bastante aceitável para os adoquins, visto que valores entre $0,8 \%$ e $1,2 \%$ de EPU são obtidos para as placas cerâmicas extrudadas do grupo de absorção de água AIII. Soma-se a esse fato que em sua aplicação não são utilizadas juntas de assentamento rígidas, de forma a permitir a absorção de tais expansões sem causar comprometimento no sistema de intertravamento.

Quanto à resistência ao ataque químico, todos os corpos de prova cerâmicos testados, com e sem adição de rejeitos e queimados entre $850{ }^{\circ} \mathrm{C}$ e $1.000{ }^{\circ} \mathrm{C}$, apresentaram classificação UA (para cloreto de amônio de $100 \mathrm{~g} / \mathrm{L}$ e hipoclorito de sódio de $20 \mathrm{mg} / \mathrm{L}$ ) e ULA (com mudança de aspecto superficial para os agentes de ataque ácido cítrico de $100 \mathrm{~g} / \mathrm{L}$, ácido clorídrico a 3\% e hidróxido de potássio de $30 \mathrm{~g} / \mathrm{L}$ ), que representa a classificação de maior resistência ao ataque químico para placas cerâmicas de revestimento segundo a norma NBR 13818 (ABNT, 1997).

\section{Criação de novos designs para os pavimentos intertravados de cerâmica}

A partir da revisão bibliográfica realizada, considerando todos os requisitos funcionais e técnicos, foi possível criar desenhos que pudessem ser posteriormente transformados em modelos de pavimentos intertravados de cerâmica - adoquins. Cada desenho desenvolvido levou em conta o processo de produção no qual seria produzido o adoquim, ou seja, o processo de extrusão. Em função desse tipo de conformação de massa, alguns cuidados durante a concepção de formas devem ser levados em conta, pois a extrusão limita alguns tipos de modelos. Dessa forma, foram desenvolvidos três pavimentos intertravados de cerâmica com design diferenciado e com a introdução de cacos cerâmicos ou chamote em sua formulação. Na Figura 7 são apresentados os modelos de pavimentos intertravados cerâmicos desenvolvidos e selecionados para os trabalhos em escala laboratorial.

Para obtermos as pavimentações, foi simulado, em escala reduzida, o assentamento mecânico dos pavimentos intertravados cerâmicos utilizando materiais permeáveis como areias de variadas granulometrias: areia grossa como base para colocação; areia média para assentamento; e areia fina para rejuntamento. Na Figura 8 é mostrado o processo de pavimentação.

Também se faz uma avaliação do comportamento estético dos pavimentos intertravados de cerâmica desenvolvidos em sua pavimentação (Figura 9).

Os três modelos desenvolvidos foram submetidos a registros de desenho industrial sob os números:

(a) BR 3020130026400 , protocolizado em 04/06/2013 (Modelo 1);

(b) BR 302013002639 6, protocolizado em 04/06/2013 (Modelo 2); e

(c) BR 302013002642 6, protocolizado em 04/06/2013 (Modelo 3).

\section{Figura 6 - Evolução da expansão por umidade (EPU) com a temperatura máxima de queima}

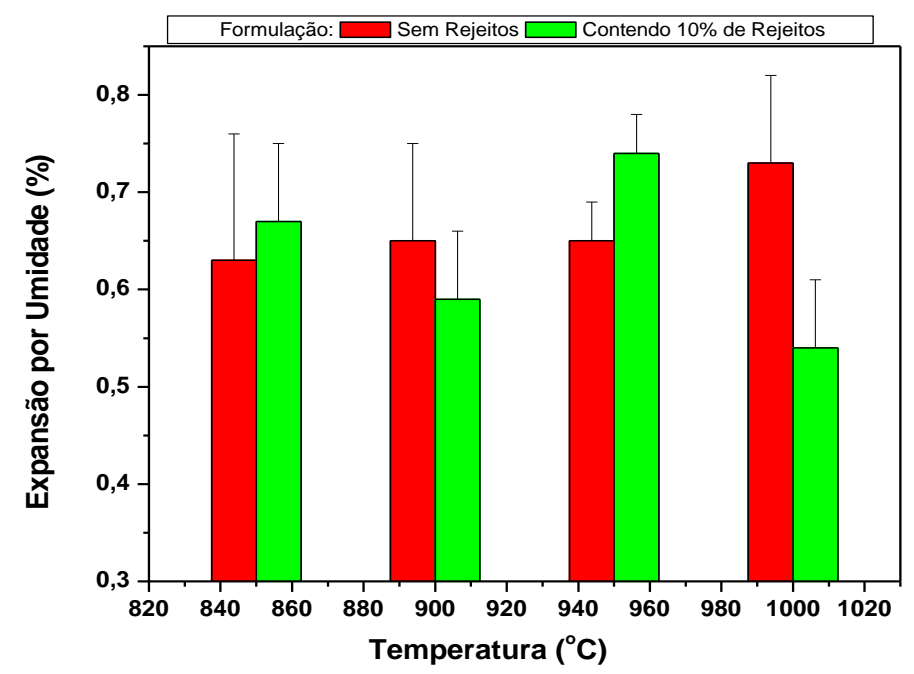

162 Dias, L. L.; Menegazzo, A. P. M.; Quinteiro, E.; Serafim, M. A. 
Figura 7 - Modelos pavimentos intertravados cerâmicos desenvolvidos

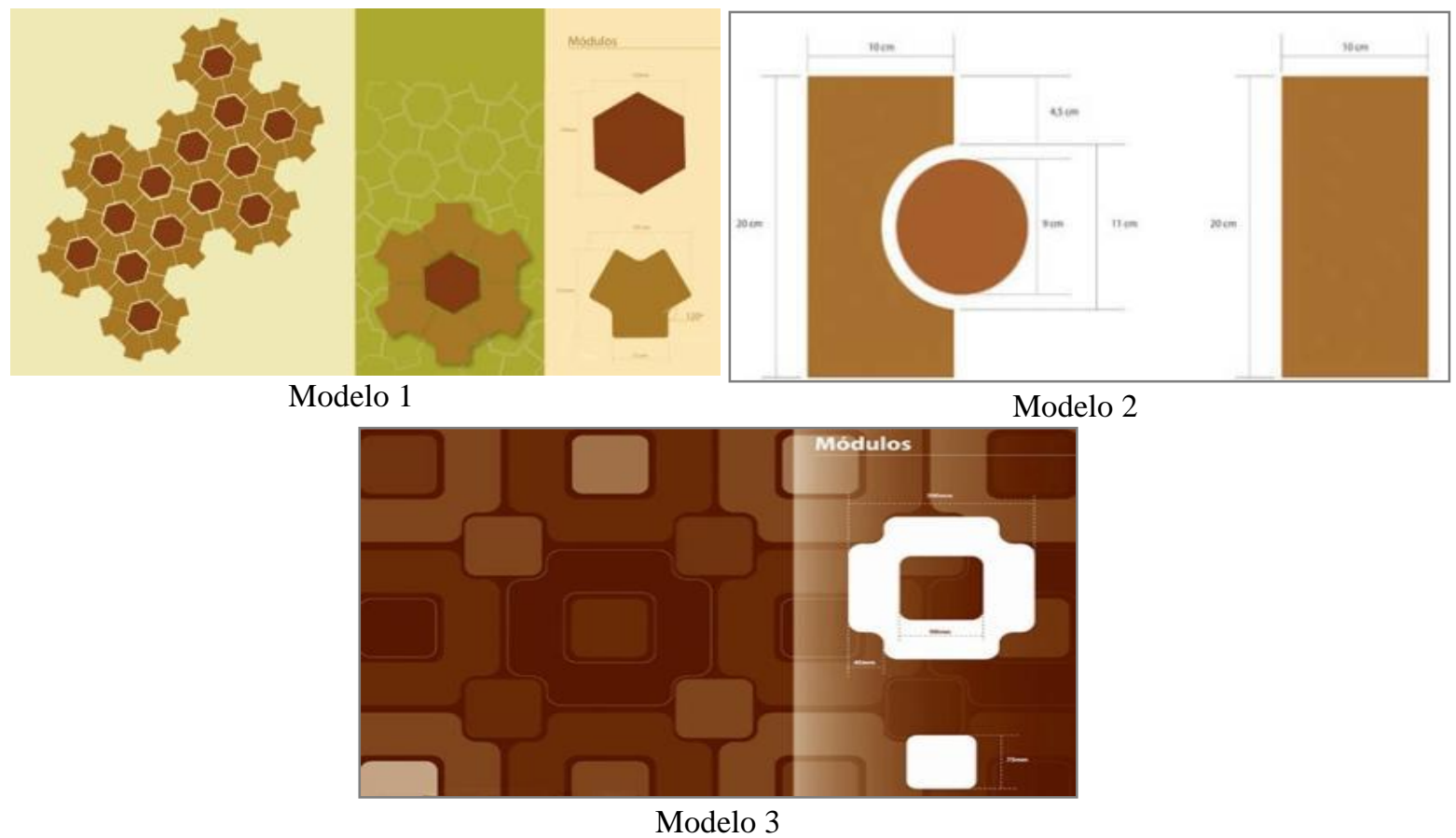

Figura 8 - Ilustração do processo de assentamento do adoquim utilizando areais de diversas granulometrias

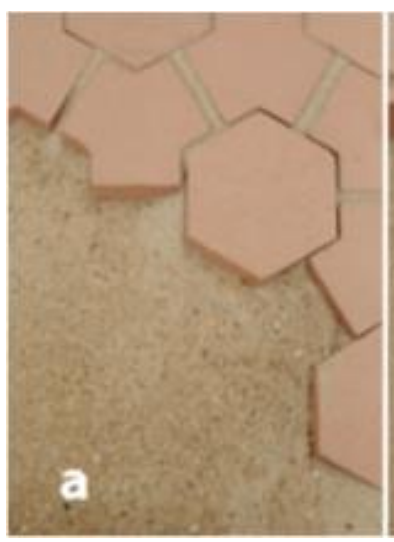

(a) Areia grossa

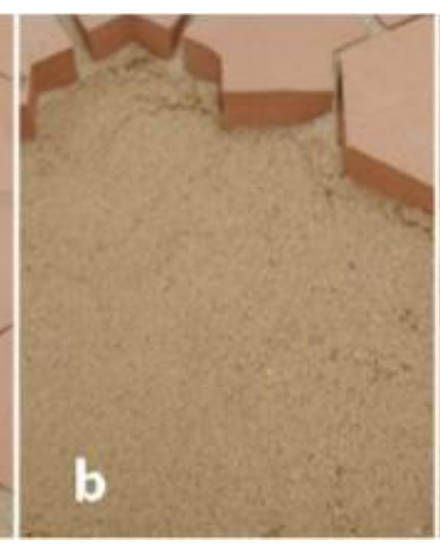

(b) Areia média

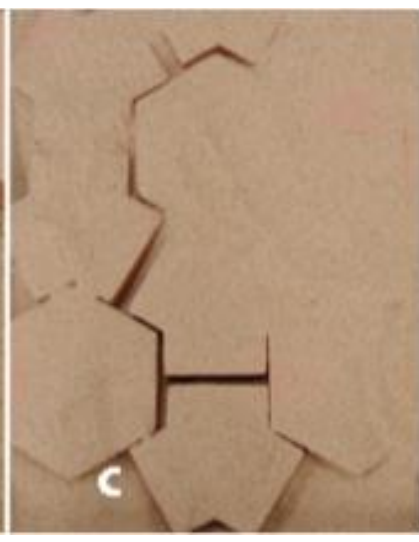

(c) Areia fina

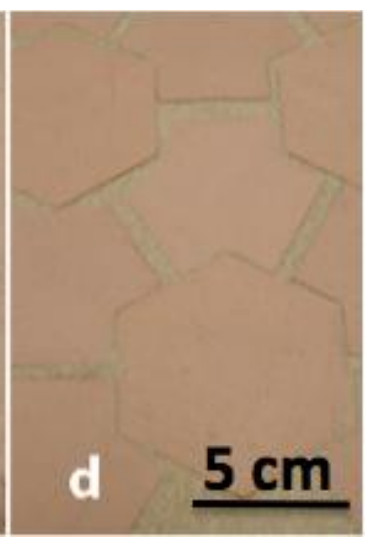

(d) Resultado

Figura 9 - Pavimentação dos pavimentos intertravados

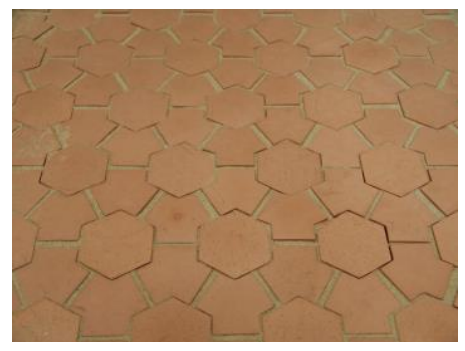

Modelo 1

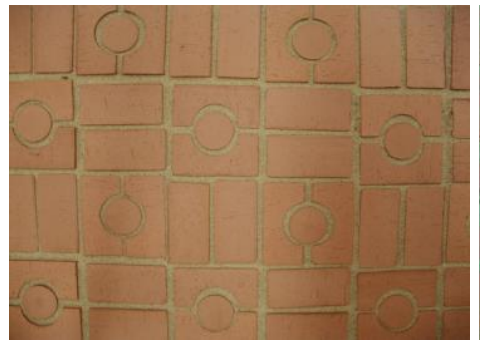

Modelo 2

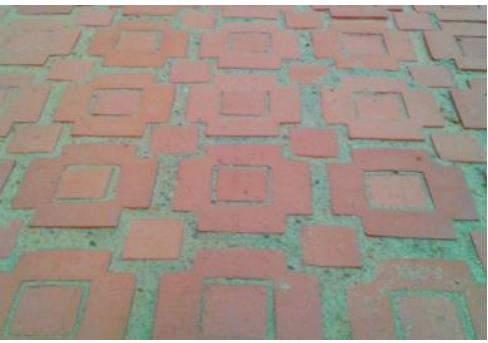

Modelo 3 
Figura 10 - Logotipo criado para a marca “Adoquim.br"

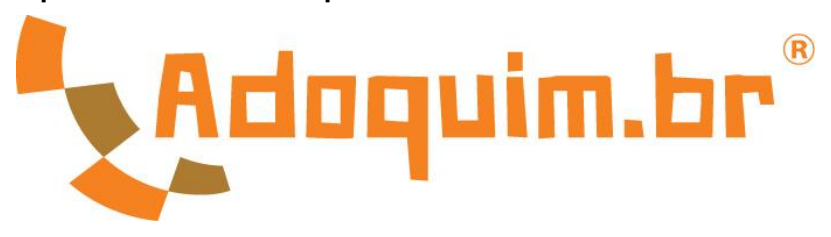

O resultado estético dos adoquins desenvolvidos foi bastante satisfatório em razão da coloração natural obtida através da queima, e o design deles favoreceu o intertravamento das peças.

\section{Criação de uma identidade visual para esta nova tipologia de produtos}

Outro ponto importante do projeto foi o desenvolvimento de uma marca que simbolizasse o produto desenvolvido, o pavimento intertravado de cerâmica. Para isso foi criado o logotipo para a marca "Adoquim.br", mostrado na Figura 10. A proposta da marca é criar uma identificação simbólica com o local de origem e com as características intrínsecas ao produto que o tornam uma solução natural e rústica. Segundo Dicio (2009), "adoquim" é um substantivo masculino que provém do árabe, “ad+dakki", cuja significação é esquina, canto, ângulo. Esse termo é muito utilizado na Espanha e em países de língua espanhola, com o significado de pedra ou bloco trabalhado em forma retangular que se utiliza na construção de pavimentos, porém utilizado especificamente para os pavers e bloquetes desenvolvidos em materiais cerâmicos e com diferentes formatos. O.$b r$ é para identificar a origem do produto.

Nesse sentido foi feita a solicitação do registro da marca "ADOQUIM.BR" e de seu logotipo, que consta em NCL(10) 19 Processo No 906294347 , protocolizado em 27 de maio de 2013, em análise preliminar cronológica do Instituto Nacional de Propriedade Industrial, a ser publicado na Revista da Propriedade Industrial (RPI).

\section{Conclusões}

A partir dos resultados apresentados pode-se concluir que:

(a) a utilização dos rejeitos produzidos pela própria indústria cerâmica como chamote mostrouse viável diante dos resultados;

(b) existe a possibilidade de aplicação dos pavimentos intertravados de cerâmica com adição de $10 \%$ de rejeitos para a pavimentação de passeios e áreas públicas, tais como praças e parques, como amplamente utilizado em países como Colômbia e Espanha;

(c) o resultado estético da pavimentação com os intertravados de cerâmica foi bastante satisfatório em razão de sua coloração, obtida através da queima e dos novos designs; e

(d) o design dos produtos também favoreceu o intertravamento do sistema.

\section{Referências}

\section{ASSOCIAÇÃO BRASILEIRA DE CIMENTO PORTLAND. Manual de Pavimento}

Intertravado. São Paulo, 2009. Disponível em: <http://www.abcp.org.br/ solucoesparacidades/colaborativo/download.php?s et=passeio_publico >. Acesso em: 29 set. 2014.

\section{ASOCIACIÓN ESPAÑOLA DE}

NORMALIZACIÓN Y CERTIFICACIÓN. UNE-

EN 1344: adoquines de arcilla cocida:

especificaciones y métodos de ensayos. Madrid, 2002.

\section{ASSOCIAÇÃO BRASILEIRA DE NORMAS}

TÉCNICAS. NBR 9781: peças de concreto para pavimentação: especificação e métodos de ensaio. Rio de Janeiro, 2013.

\section{ASSOCIAÇÃO BRASILEIRA DE NORMAS}

TÉCNICAS. NBR 13818: placas cerâmicas para revestimentos: especificação e métodos de ensaio. Rio de Janeiro, 1997.

\section{ASSOCIAÇÃO NACIONAL DA INDÚSTRIA} DE CERÂMICA VERMELHA. Setor. Disponível em: <http://portal.anicer.com.br/setor/>. Acesso em: 10 out. 2014.

\section{CRUZ, L. O. M. Pavimento Intertravado de}

Concreto: estudo dos elementos e métodos de dimensionamento. Rio de Janeiro, 2003.

Dissertação (Mestrado em Engenharia Civil) Escola de Engenharia, Universidade Federal do Rio de Janeiro, Rio de Janeiro, 2003.

DICIO. Adoquim. 2009. Disponível em: $<$ http://www.dicio.com.br/adoquim/>. Acesso em: 09 ago. 2016. 
ESTUDOS DE MERCADO SEBRAE/ESPM:

Cerâmica vermelha para construção: telhas, tijolos e tubos. 2008. Disponível em:

<http://www.redeaplmineral.org.br/biblioteca/cera mica-vermelha/NT00038DA6.pdf >. Acesso em: 6 maio 2015.

FERNANDES, I. D. Blocos e Pavers: produção e controle de qualidade. 4. ed. São Paulo: Treino e Assessoria e Treinamentos Empresariais, 2013.

HALLACK, A. Pavimento intertravado: uma solução universal. Revista Prisma - Soluções Construtivas com Pré-Fabricados de Concreto, São Paulo, p. 25-27, dez. 2001.

MEDEIROS, H. Piso Intertravado. Revista Equipe de Obra, v. 18, jul./ago. 2008. Disponível em: <http://www.equipedeobra.com.br/construcaoreforma/18/artigo96977-1.asp >. Acesso em: 30 set. 2014.
MÜLLER, R. M. Avaliação de Transmissão de Esforços em Pavimentos Intertravados de Blocos de Concreto. Rio de Janeiro, 2005. Dissertação (Mestrado em Engenharia Civil) Escola de Engenharia, Universidade Federal do Rio de Janeiro, Rio de Janeiro, 2005.

\section{PEDREIRÃO. Assentamento de Piso}

Intertravado, Passo a Passo. 25 mar. 2014. Disponível em: <http://pedreirao.com.br/areasexternas/assentamento-de-piso-intertravado-passoa-passo/>. Acesso em: 11 ago. 2016.

\section{Agradecimentos}

Ao Conselho Nacional de Desenvolvimento Científico e Tecnológico (CNPq), pelo apoio financeiro à realização deste projeto de pesquisa.

Lilian Lima Dias

Centro Cerâmico do Brasil | Rua Roque Cecagno, Esq. c/ Av Eduardo Cocco, s/n, Jardim D'Itália II | Santa Gertrudes - SP - Brasil | CEP 13510-000 | Tel.: (19) 3545-9090 | E-mail: lilian@ccb.org.br

Ana Paula Margarido Menegazzo

Centro Cerâmico do Brasil | Tel.: (19) 3545-3636 | E-mail: anapaula@ccb.org.br

Eduardo Quinteiro

Universidade Federal de São Paulo | Rua Talim, 330, Sala 225 | São José dos Campos - SP - Brasil | CEP 12231-280 | Tel.: (12) 3309-9605 | E-mail: eduardoquinteiro@gmail.com

Marcos Antônio Serafim

CCB Design | Centro Cerâmico do Brasil | E-mail: serafim@ccb.org.br

Revista Ambiente Construído

Associação Nacional de Tecnologia do Ambiente Construído

Av. Osvaldo Aranha, $99-3^{\circ}$ andar, Centro

Porto Alegre - RS - Brasil

CEP 90035-190

Telefone: +55 (51) 3308-4084

Fax: +55 (51) 3308-4054

www.seer.ufrgs.br/ambienteconstruido

E-mail: ambienteconstruido@ufrgs.br 